\title{
REVERSIBLE DENATURATION IN THE MYOSIN ADENOSINE TRIPHOSPHATASE SYSTEM ${ }^{1}$
}

\author{
KARL F. GUTHE AND DUGALD E. S. BROWN \\ Department of Zoology, University of Michigan \\ Ann Arbor, Michigan \\ ONE FIGURE
}

The influence of temperature, pressure and $\mathrm{pH}$ on the adenosine triphosphatase (ATPase) activity of myosin as set forth in the paper by Brown et al. ('58) is very similar to their influence on bacterial luminescence (Brown, Johnson and Marsland, '42). The satisfactory application of the theory of absolute reaction rates to the luminescence data (Eyring and Magee, '42) suggests its application to the myosin data.

According to this theory, a rate process is in fact an unstable equilibrium between an activated complex and its reactants (Glasstone, Laidler and Eyring, '41; Johnson, Eyring and Polissar, '54). The equilibrium constant for this equilibrium is customarily represented by the symbol $\mathrm{K}^{*}$. The specific reaction rate constant, $k^{\prime}$, is

$$
\mathrm{k}^{*}=\kappa \frac{\mathrm{kT}}{\mathrm{h}} \mathrm{K}^{*}
$$

in which $\mathrm{k}=$ transmission coefficient

$\mathrm{k}=$ Boltzmann constant

$\mathrm{h}=$ Planck's constant

$\mathrm{T}=$ absolute temperature

The transmission coefficient can usually be taken as unity, and the term $\mathrm{kT} / \mathrm{h}$ has the numerical value $5.56 \times 10^{12}$ at $0^{\circ} \mathrm{C}$.

1 This investigation was aided by grants from the Dazian Foundation for Medical Research, the Cinchona Products Institute, Inc., and the Horace H. Rackham School for Graduate Studies, University of Michigan. 
Like any ordinary equilibrium constant, $\mathrm{K}^{*}$ can be related to thermodynamic values for free energy, heat, entropy and volume. Thus the effect of pressure on a rate process depends on the difference in volume between the activated complex and its reactants.

Brown et al. ('58) have shown that the following reactions occur in the myosin ATPase system:

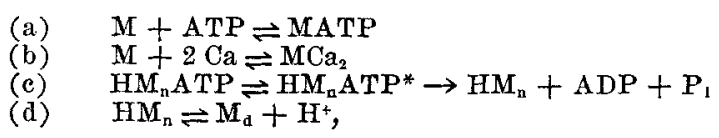

where $M$ is myosin, $M_{n}$ is native myosin, $M_{d}$ is reversibly denatured myosin, ATP is adenosine triphosphate, ADP is adenosine diphosphate, $\mathrm{P}_{1}$ is inorganic phosphate, and * denotes the activated complex. It is not known whether denatured myosin combines with calcium ion and ATP or not. In any event, only (c) and (d) are concerned with the response of the system to pressure, temperature and $\mathrm{pH}$ under the experimental conditions of Brown et al. Reaction (a) was driven strongly to the right by the use of very high substrate concentrations, and reaction (b) was shown to be insensitive to temperature and pressure.

Myosin ATPase activity $(v)$ is measured by determining the rate of increase of inorganic phosphate:

$$
\nabla=\frac{\partial\left(P_{i}\right)}{\partial t}=k^{\prime}{ }_{c}\left(H_{n} A T P\right),
$$

where parentheses denote concentration. At high substrate concentration, $\left(\mathrm{HM}_{\mathrm{n}} \mathrm{ATP}\right)$ is very nearly equal to the total amount of active enzyme $\left(\mathrm{HM}_{\mathrm{n}}\right)$,

For reaction (d),

$$
\left(H M_{n} A T P\right) \simeq\left(H M_{n}\right) .
$$

$$
\mathbf{K}_{\mathrm{d}}=\frac{\left(\mathrm{H}^{+}\right)\left(\mathrm{M}_{\mathrm{d}}\right)}{\left(\mathrm{HM}_{\mathrm{n}}\right)} .
$$

The total amount of native and inactivated enzyme $\left(M_{t}\right)$, is constant for any set of experiments, and is given by

$$
\left(M_{t}\right)=\left(H_{n}\right)+\left(M_{d}\right)=\left(H_{n}\right)+\frac{K_{d}}{\left(H^{+}\right)}\left(H M_{n}\right) \text {, }
$$


so that

$$
\left(\mathrm{HM}_{\mathrm{n}}\right)=\frac{\left(\mathrm{M}_{\mathrm{t}}\right)}{1+\frac{\mathrm{K}_{\mathrm{a}}}{\left(\mathrm{H}^{+}\right)}} \cdot
$$

Substituting (6) in (3) and then (3) in (2), we have for the activity

$$
\mathbf{\nabla}=\mathbf{k}_{c}^{\prime} \frac{\left(\mathbf{M}_{\mathrm{t}}\right)}{1+\frac{\mathbf{K}_{\mathrm{d}}}{\left(\overline{\mathrm{H}}^{+}\right)}} .
$$

Qualitatively, it is clear that when $\left(\mathrm{H}^{+}\right)$is much larger than $K_{d}$ (when the equilibrium favors the native myosin) the observed rate of hydrolysis for a fixed amount of myosin will depend only on the specific rate constant for (c). The observations at $\mathrm{pH} 6.3$ show that pressure decreases this rate constant.

On the other hand, at higher $\mathrm{pH}$ the equilibrium becomes more and more favorable to the inactive myosin. Since the activity at atmospheric pressure increases with $\mathrm{pH}$, the specific rate constant for (c) must also be $\mathrm{pH}$ sensitive, increasing with $\mathrm{pH}$ so rapidly that it masks the effect of inactivation. Later in this analysis, it will be shown that, as Mommaerts ('54) has already suggested, $\mathrm{k}_{\mathrm{c}}$ increases in direct proportion to the hydroxyl ion concentration. Although pressure decreases the rate constant $\mathrm{k}_{c}^{\prime}$, it increases the measured activity v. Equilibrium (d) must therefore also be pressure-sensitive, pressure favoring the native form. Since pressure increases the activity at alkaline $\mathrm{pH}$, more than enough denatured enzyme must be reactivated to outweigh the pressure inhibition per active site, or, in other words, the volume change in the equilibrium must be larger than that in the rate process.

As in the luminescence analysis, one can replace $k_{c}$ and $\mathrm{K}_{\mathrm{d}}$ by

$$
k_{c}^{\prime}=k^{\prime \prime}{ }_{c} \frac{k T}{h} e^{-\frac{\Delta E^{*}+p \Delta \Delta V^{*}-T \Delta S^{*}}{R T}}
$$

and

$$
K_{d}=e^{-\frac{\Delta E+p \Delta V-T \Delta S}{R T}},
$$


where $\mathrm{k}^{\prime \prime}$ still varies with $\mathrm{pH}$, although its variation with temperature and pressure has been removed. Then (7) becomes

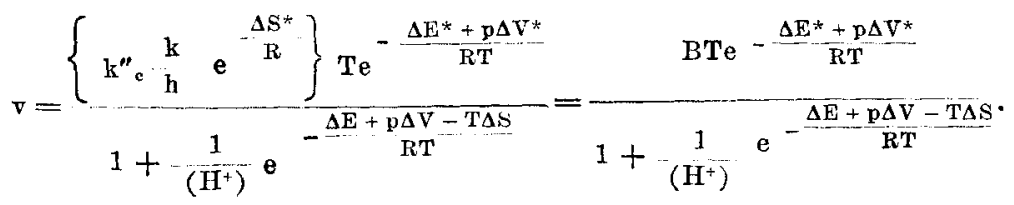

In this equation, $\mathrm{B}$ in the final expression replaces the bracket, which contains unknown factors that are independent of temperature and pressure but still $\mathrm{pH}$-dependent.

At low $\mathrm{pH}$, where a negligible fraction of the myosin is denatured, (10) becomes

$$
\mathrm{v}=\mathrm{BTe}-\frac{\Delta \mathrm{E}^{*}+\mathrm{p} \Delta \mathrm{V}^{*}}{\mathrm{RT}} .
$$

The ratio of the activity $v_{p}$ at pressure $p$ to the activity $v$ at atmospheric pressure at the same temperature is then

$$
\nabla_{\mathrm{r}} / \mathrm{v}=\mathrm{e}^{-\frac{\mathrm{p} \Delta \mathrm{V}^{*}}{\mathrm{RT}}} \text {. }
$$

The difference in volume between the activated complex and the reactants can therefore be determined from the extent of inhibition of activity by pressure at $\mathrm{pH}$ 6.3. The activity at this $\mathrm{pH}$ under $7800 \mathrm{psi}$ is $31 \%$ of the activity at atmospheric pressure so that the volume of the activated complex is 56 $\mathrm{cm}^{3} /$ mole larger than the volume of the reactants.

At higher $\mathrm{pH}$, where the effect of reversible denaturation cannot be neglected, the ratio $v_{p} / v$ at constant temperature and $\mathrm{pH}$ is

$$
\mathrm{v}_{p} / \mathrm{v}=\mathrm{e}^{-\frac{\mathrm{p} \Delta \mathrm{V}^{*}}{\mathrm{RT}}} \frac{1+\frac{1}{\left(\mathrm{H}^{+}\right)} \mathrm{e}^{-\frac{\Delta \mathrm{E}-\mathrm{T} \Delta \mathrm{S}}{\mathrm{RT}}}}{1+\frac{1}{\left(\mathrm{H}^{+}\right)} \mathrm{e}^{-\frac{\Delta \mathrm{E}+\mathrm{p} \Delta \mathrm{V}-\mathrm{T} \Delta \mathrm{S}}{\mathrm{RT}}}} \cdot
$$

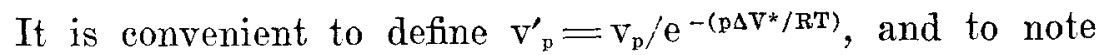
that the equilibrium constant for reversible denaturation 
at pressure $\mathrm{p}$ is

$$
\mathbf{K}_{\mathbf{p}}=\mathrm{e}^{-\frac{\Delta \mathbf{E}+\mathbf{p} \Delta \mathrm{V}-\mathrm{T} \Delta \mathrm{S}}{\mathrm{RT}}}
$$

With these substitutions, equation (13) becomes

$$
{v^{\prime}}_{p} / v=\frac{1+\frac{K_{p}}{\left(H^{+}\right)}\left(e^{-\frac{p \Delta V}{R T}}\right)}{1+\frac{K_{p}}{\left(H^{+}\right)}}=\frac{\left(H^{+}\right)+K_{p} e^{\frac{p}{R T V}}}{\left(H^{+}\right)+\bar{K}_{p}} .
$$

To estimate $K_{p}$ and $\Delta V$, the volume difference between native and denatured myosin, it is convenient to use the corrected pressure increment

$$
\mathrm{v}_{\mathrm{p}}^{\prime} / \mathrm{v}-1=\frac{\mathbf{K}_{\mathrm{p}}}{\left(\mathrm{H}^{+}\right)+\overline{\mathbf{K}}_{\mathrm{p}}}\left(\mathrm{e}^{\mathrm{p} \Delta^{\mathrm{V}} / \mathrm{BT}}-\mathrm{J}\right) .
$$

Brown et al. include a plot of this increment against $\mathrm{pH}$ and the shape of their curve is consistent with equation (15); the numerical values obtained from the graph are $\mathrm{pK}_{\mathrm{p}}=7.85$ at 7800 psi and $\Delta V=97 \mathrm{~cm}^{3} /$ mole, the denatured form having the larger volume. Reversible denaturation, then, proceeds with a large increase in volume. When $\Delta \mathrm{V}$ is known, the $\mathrm{pK}$ for the dissociating hydrogen ion at atmospheric pressure can be calculated, and it is 6.96. The size of the volume increase shows that reaction (d) is more than a simple acidbase equilibrium. The reaction must involve extensive configurational changes as well, and can therefore properly be termed a reversible denaturation. It is probably more than coincidence that a very similar volume change is found for the gelation of myosin, the gel form, like the denatured form, having the larger volume.

At this point in the analysis it becomes possible to show the $\mathrm{pH}$-dependence of the activity of a native enzymatic site. From the equilibrium constant, one can calculate the fraction of the sites inactivated at each $\mathrm{pH}$. The activity per active site $\left(\mathrm{BTe}^{-(\Delta E / R T)}\right)$ is then determined by dividing the observed activity by the fraction active. The result is shown in figure 1. The straight line in the figure, which fits the points well above 
$\mathrm{pH} 7$, has a slope of one. The rate then is inversely proportional to the first power of the hydrogen ion concentration, or directly proportional to the hydroxyl ion concentration. This relationship was found by Mommaerts ('54) for myosin ATPase between $\mathrm{pH} 7$ and 9 in $0.15 \mathrm{M} \mathrm{KCl}$. In the present data, activities below $\mathrm{pH} 7$ are larger than the linear relation

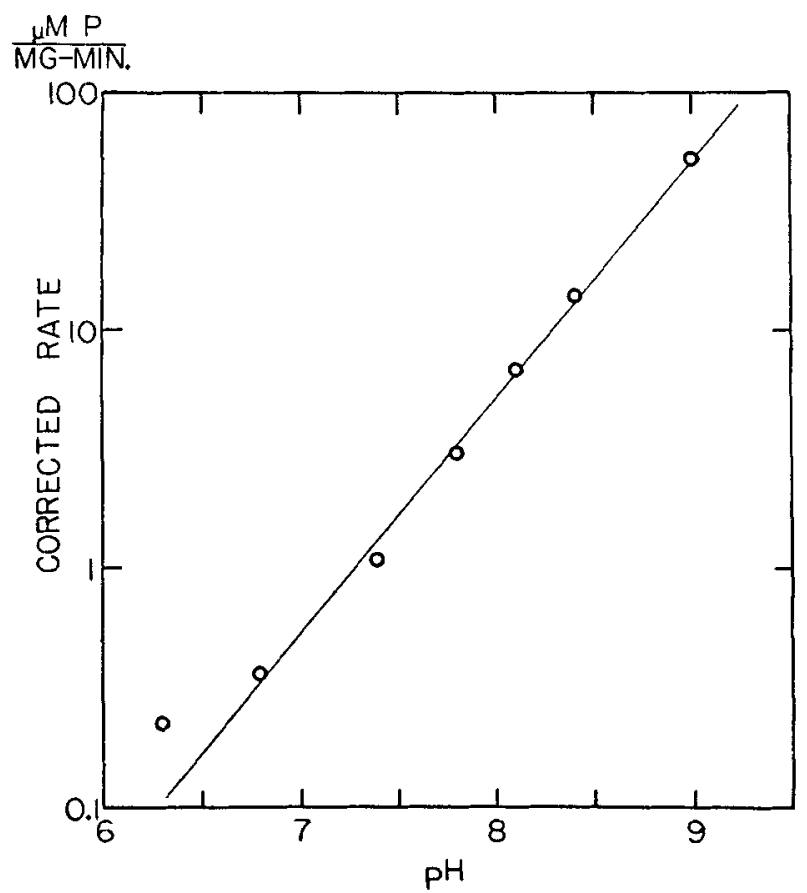

Fig. 1 The pH dependence of the rate of ATP hydrolysis per active site, after correction for the fraction reversibly denatured (see text).

predicts. Perhaps another reaction enters below $\mathrm{pH} 7$, as is indicated by the large peak in activity that Mommaerts finds at $\mathrm{pH} 6.2$ in $0.15 \mathrm{M} \mathrm{KCl}$.

Another possible explanation of the data might be that two active forms of enzyme were present, a more active alkaline form and a less active acid form. If this were so, calculation shows that pressure would decrease the rate constant for the acid form, increase that for the alkaline form to the same extent, and favor the acid form in the equilibrium between the two. This is not a very satisfying result, 
and although the scheme fits the pH data satisfactorily, it fails to account for the observed shape of the activity : pressure curve (fig. 5 of Brown et al.) More complicated reaction schemes could be assumed in which hydrolysis of ATP is catalyzed by either $\mathrm{H}^{+}$or $\mathrm{OH}^{-}$in the presence of the enzyme, while the enzyme is reversibly denatured by either acid or alkaline $\mathrm{pH}$. It seems premature to present an extended analysis based on a more complicated scheme without more extensive data.

At present, the $\mathrm{pH}$ dependence of the ATPase activity is left undefined, as part of term B in equation (10), and we proceed to the other thermodynamic constants. Although it may now seem easy to evaluate the energies and the entropy, there is an added complication. The volume changes were determined at a single temperature, but they are temperaturedependent, as are the volume changes for both rate and equilibrium constants in bioluminescence (Eyring and Magee, '42). Activities at $0^{\circ} \mathrm{C}$, although less precisely determined than the much larger activities at $30^{\circ} \mathrm{C}$, show clearly that pressure has little if any effect at any pH. If the volume changes at $0^{\circ} \mathrm{C}$ are taken as zero, within experimental error, the volume changes depend on temperature as follows:

$$
\begin{aligned}
& \Delta \mathrm{V}^{*}=-483+1.77 \mathrm{~T} \\
& \Delta \mathrm{V}=-882+3.23 \mathrm{~T} .
\end{aligned}
$$

The corresponding relations for luminescence (Eyring and Magee, '42) are

$$
\begin{aligned}
& \Delta \mathrm{V}^{*}=546-1.81 \mathrm{~T} \\
& \Delta V=-923+3.21 \mathrm{~T} \text {. }
\end{aligned}
$$

Whether or not the numerical agreement between the coefficients in (17) and (18) is coincidence, it deserves mention.

Once the preceding values for the volume changes are adopted, the remaining constants of equation (10) can be determined. Not only the $\mathrm{pH}$ data, but also the activity: temperature and the activity: pressure data of Brown et al. are fitted satisfactorily by equation (19),

$$
\nabla=\frac{3.3 \times 10^{23} \mathrm{Tf}_{\mathrm{H}} \times 10-\left[\frac{7410}{\mathrm{~T}}+\mathrm{p}\left(\frac{-2.56}{\mathrm{~T}}+0.00937\right)\right]}{\left.1+\frac{9.0 \times 10^{8}}{\left(\mathrm{H}^{+}\right)} \times 10^{-\left[\frac{4120}{\mathrm{~T}}+\mathrm{p}\right.}\left(-\frac{4.67}{\mathrm{~T}}+0.0171\right)\right]}
$$


where $\mathrm{v}$ is measured in micromoles ATP split in one minute by one milligram of myosin, $p$ is measured in atmospheres, and $f_{\mathrm{H}}$ is an undetermined function of $\mathrm{pH}$ that is equal to one at $\mathrm{pH}$ 8.4. This leads to the following values of the constants in $(10)$ :

$$
\begin{aligned}
& \Delta \mathrm{E}^{*}=34,000 \mathrm{cal} / \mathrm{mole} ; \quad \Delta \mathrm{V}^{*}=-483 \pm 1.77 \mathrm{~T} \text { in } \mathrm{cm}^{3} / \mathrm{mole} \\
& \Delta \mathrm{E}=18,900 \mathrm{cal} / \mathrm{mole} ; \quad \Delta \mathrm{S}=32 \mathrm{E} . \mathrm{U} . ; \quad \Delta \mathrm{V}=-882+3.23 \mathrm{~T} \text { in } \mathrm{cm}^{3} / \mathrm{mole} .
\end{aligned}
$$

These constants are somewhat different from those of luminescence. The activation energy of $34,000 \mathrm{cal} / \mathrm{mole}$ for the rate process (c) is large. The energy of reaction of $18,900 \mathrm{cal} /$ mole for equilibrium (d) is unusually low for a reversible denaturation. The entropy change on denaturation is also relatively small. Entropy, or disorder, increases on denaturation, as expected, but not very much. Most denaturations show an entropy increase of the order of 200 entropy units (Johnson, Eyring and Polissar, '54). This suggests that reversibly denatured myosin still retains a well ordered structure. The numerical values of all these thermodynamic constants are sensitive to the values taken for the temperature dependence of the volume changes and must be regarded not as final figures but as indications of the correct order of magnitude.

In the present paper, reversible denaturation has been regarded as identical with the hydrogen ion dissociation. The inactivated enzyme might, however, exist in two forms, with and without the dissociated hydrogen ion. This would modify equation (7) to read as follows:

$$
\mathrm{v}=\mathrm{k}_{\mathbf{d}}^{\prime} \frac{\mathbf{M}_{\mathrm{t}}}{1+\mathrm{K}_{\mathbf{d}}^{\prime}\left(1+\frac{\bar{K}_{\mathbf{h}}}{\left(\mathbf{H}^{+}\right)}\right)}
$$

where $K^{\prime}{ }_{d}$ is the equilibrium for reversible dissociation and $\mathrm{K}_{\mathrm{h}}$ the dissociation constant of the acid species of denatured myosin. Either equation will fit the present data equally well. The scatter in the pressure: $\mathrm{pH}$ data suggests that there may be pressure-insensitive differences between preparations, which might be referred to differences in $K_{d}^{\prime}$ of equation (7a). The scatter may, however, also be caused by sensitivity of 
the original $K_{d}$ to factors other than hydrogen ion concentration. The difference in the apparent activation energies of the precipitated and the dialyzed myosins of Brown et al. ('58) may also be referred to one or the other of these possibilities.

\section{SUMMARY}

Expressions are derived for the interpretation, on the basis of absolute reaction rate theory, of pressure, temperature and hydrogen ion influences on myosin adenosine triphosphatase activity.

Numerical data that fit the experimental results of Brown and co-workers include the following, which suggest the correct order of magnitude for the thermodynamic values:

(a) in the reversible denaturation of myosin, $\Delta \mathrm{E}$ is 18,900 $\mathrm{cal} / \mathrm{mole}, \Delta \mathrm{S}$ is $32 \mathrm{cal} / \mathrm{mole}$-degree, and $\Delta \mathrm{V}$ is $(-882+3.23 \mathrm{~T})$ $\mathrm{cm}^{3} /$ mole.

(b) for the breakdown of the myosin ATP complex, $\Delta \mathrm{E}^{*}$ is $34,000 \mathrm{cal} / \mathrm{mole}$, and $\Delta \mathrm{V}^{*}$ is $(-483+1.77 \mathrm{~T}) \mathrm{cm}^{3} / \mathrm{mole}$.

\section{LITERATURE CITED}

Brown, D. E. S., K. F. Guthe, H. C. Iawler and M. P. Carpenter 1958 The pressure, temperature and ion relations of myosin ATPase. J. Cell. and Comp. Physiol., 52: 59-78.

Brown, D. E. S., F. H. Johnson ANd D. A. Marsland 1942 The pressuretemperature relations of bacterial luminescence. Ibid., 20 : 151-168.

Erring, H., AND J. L. MAGEE 1942 Application of the theory of absolute reaction rates to bacterial luminescence. Ibid., 20: 169-177.

Glasstone, S., K. J. Laidler and H. Exring 1941 The Theory of Rate Processes. MeGraw-Hill, New York.

Johnson, F. H., H. Eyring and M. J. Polissar 1954 The Kinetic Basis of Molecular Biology. John Wiley and Sons, New York.

Mommaerts, W. F. H. M., AND I. GREen 1954 Adenosinetriphosphatase systems of muscle. III. A survey of the adenosinetriphosphatase activity of inyosin. J. Biol. Chem., 208: 833-843. 